\title{
Percepção de estudantes e professores sobre a agroecologia no arquipélago do
}

\section{Marajó, Brasil}

\author{
Perception of students and teachers about agroecology in the Marajó archipelago, Brazil \\ Percepción de estudiantes y docentes sobre agroecología en el archipiélago de Marajó, Brasil
}

Recebido: 13/01/2021 | Revisado: 18/01/2021 | Aceito: 25/01/2021 | Publicado: 27/01/2021

Fernando Luís Couto da Silva Júnior

ORCID: https://orcid.org/0000-0001-7885-5525 Instituto Federal de Educação, Ciência e Tecnologia do Pará, Brasil E-mail: flc3136@gmail.com

Julia Siqueira Moreau

ORCID: https://orcid.org/0000-0002-0107-9262 Instituto Federal de Educação, Ciência e Tecnologia do Pará, Brasil E-mail: julia.moreau@ifpa.edu.br

Fabricio Nilo Lima da Silva

ORCID: https://orcid.org/0000-0002-6402-0540 Instituto Federal de Educação, Ciência e Tecnologia do Pará, Brasil E-mail: fabricio.nilo@ifpa.edu.br

Wagner Luiz Nascimento do Nascimento

ORCID: https://orcid.org/0000-0003-3392-881X Instituto Federal de Educação, Ciência e Tecnologia do Pará, Brasil E-mail: wagner.nascimento@ifpa.edu.br

Hericley Serejo Santos

ORCID: https://orcid.org/0000-0002-0483-899X Instituto Federal de Educação, Ciência e Tecnologia do Pará, Brasil E-mail: hericley.serejo@ifpa.edu.br

Ana Célia Barbosa Guedes

ORCID: https://orcid.org/0000-0003-4212-2252 Instituto Federal de Educação, Ciência e Tecnologia do Pará, Brasil E-mail: anacelia.guedes@ifpa.edu.br

\begin{abstract}
Resumo
O objetivo deste trabalho foi avaliar a percepção de estudantes e professores sobre a agroecologia nas escolas da zona urbana e rural do município de Breves, arquipélago do Marajó, Pará. O estudo foi realizado nas escolas de ensino fundamental II, entre janeiro e fevereiro 2020. Foi utilizada uma pesquisa descritiva exploratória, por meio de aplicação de questionários, para 94 estudantes do $9^{\circ}$ ano e 16 professores das disciplinas de geografia e ciências. Os dados foram analisados em gerenciador de planilhas eletrônicas e apresentados em formato de gráficos. Os resultados obtidos revelam que a maioria (60\%) e (75\%) dos estudantes, são do sexo masculino, com idades entre 14-15 e 16-17 anos, tanto na zona urbana e rural, respectivamente. A forma mais comum de acesso ao tema por esses estudantes tem sido via televisão e quando abordado em sala, na maioria das vezes, por meio do quadro. A maioria dos professores que trabalham no município estudado já ouviu falar sobre agroecologia seja pela televisão ou em ambiente acadêmico. No entanto, os professores da zona urbana debatem esporadicamente essa temática em sua aulas, já os da zona rural fazem debates relacionados à temática agroecologica sempre que possível nas aulas. Assim, os estudantes da zona rural possuem um maior conhecimento acerca de agroecologia. Por outro lado, observa-se que há pouca difusão da temática agroecológica nas escolas. Sugerimos atividades pedagógicas nas escolas do ensino fundamental tendo como tema a agroecologia, no sentido de fortalecer o ensino-aprendizagem.
\end{abstract}

Palavras-chave: Sustentabilidade; Ensino-aprendizagem; Currículo; Amazônia.

\begin{abstract}
The objective of this work was to evaluate the perception of students and teachers about agroecology in schools in the urban and rural areas of the municipality of Breves, archipelago of Marajó, Pará. The study was carried out in elementary schools, between January and February 2020. An exploratory descriptive research was used, through the application of questionnaires, for 94 students of the 9th grade and 16 teachers in the disciplines of geography and science. The data were analyzed in a spreadsheet manager and presented in graph format. The results obtained reveal that the majority $(60 \%)$ and $(75 \%)$ of the students are male, aged between 14-15 and 16-17 years, both in urban and rural areas, respectively. The most common form of access to the topic by these students has been via television and when approached in the classroom, most of the time, through the blackboard. Most teachers who work in the studied municipality have heard about agroecology either on television or in an academic environment. However, teachers in
\end{abstract}


the urban area debate this theme sporadically in their classes, while those in the rural area make debates related to the agroecological theme whenever possible in class. Thus, rural students have greater knowledge about agroecology. On the other hand, it is observed that there is little dissemination of the agroecological theme in schools. We suggest pedagogical activities in elementary schools with the theme of agroecology, in order to strengthen teaching and learning. Keywords: Sustainability; Teaching-learning; Curriculum; Amazon.

\section{Resumen}

El objetivo de este trabajo fue evaluar la percepción de estudiantes y docentes sobre la agroecología en escuelas del área urbana y rural del municipio de Breves, archipiélago de Marajó, Pará.El estudio se realizó en las escuelas primarias II, entre enero y febrero de 2020. Se utilizó una investigación exploratoria descriptiva, mediante la aplicación de cuestionarios, a 94 estudiantes del $9^{\circ}$ grado y 16 docentes en las disciplinas de geografía y ciencia. Los datos se analizaron en un administrador de hojas de cálculo y se presentaron en formato gráfico. Los resultados obtenidos revelan que la mayoría (60\%) y (75\%) de los estudiantes son varones, con edades comprendidas entre 14-15 y 16-17 años, tanto en zonas urbanas como rurales, respectivamente. La forma más común de acceso al tema por parte de estos estudiantes ha sido a través de la televisión y cuando se aborda en el aula, la mayoría de las veces, a través del pizarrón. La mayoría de los docentes que laboran en el municipio estudiado han escuchado sobre agroecología ya sea en televisión o en un entorno académico. Sin embargo, los docentes del área urbana debaten este tema de manera esporádica en sus clases, mientras que los del área rural realizan debates relacionados con el tema agroecológico siempre que es posible en clase. Así, los estudiantes rurales tienen un mayor conocimiento sobre agroecología. Por otro lado, se observa que existe poca difusión del tema agroecológico en las escuelas. Sugerimos actividades pedagógicas en las escuelas primarias con el tema de la agroecología, con el fin de fortalecer la enseñanza y el aprendizaje.

Palabras clave: Sustentabilidad; Enseñanza-aprendizaje; Plan de estudios; Amazonia.

\section{Introdução}

Agroecologia é definida como um método "mais natural" ou "menos agressivo", para o homem e a natureza (Luz \& Quiñones, 2012). Assim, é uma ciência multidisciplinar que orienta, por exemplo, a população a realizar uma agricultura sustentável, respeitando o ecossistema em suas potencialidades e limitações (Caporal \& Costabeber, 2002; Altieri, 2010; Koller \& Sobral, 2010), além de se constituir como um campo do conhecimento científico que parte de um enfoque holístico e de uma abordagem sistêmica (Caporal, 2009). Desse modo, nas últimas décadas houve um crescimento significativo dos estudos sobre agroecologia (Burigo \& Porto, 2019; Santos, 2020).

Desde o período de formação do Estado brasileiro até a contemporaneidade, o desenvolvimento nacional sempre foi uma das bandeiras dos dirigentes do país, porém a maioria dos projetos de desenvolvimentos implementados pelo Estado não consideraram os povos tradicionais que vivem em diferentes regiões, assim como os limites dos recursos naturais, o que acabou ocasionando vários impactos ao meio ambiente. Na década de 1990, um novo cenário político mundial trouxe o debate sobre a agroecologia, e nas reuniões realizadas durante a conferência Rio-92, que teve como tema o "Meio Ambiente e Desenvolvimento" (Castro, 2015), a temática agroecologia foi muito discutida por ativistas e intelectuais. A partir de então, essa ciência passou a ser tratada como relevante e necessária em vários âmbitos da sociedade.

No ambiente escolar, a agroecologia pode ser trabalhada, pensada e discutida de forma integrada (Freitas et al., 2013; Barbosa \& Araujo, 2016), como, por exemplo, nas disciplinas de história, geografia, biologia, física, química, entre outras. Diante dessa perspectiva, esse tema deve ser trabalhado tanto de forma integrada ao currículo da disciplina quanto de forma transversal no ensino-aprendizagem, principalmente nas escolas do campo (Sousa, 2017; Hage et al., 2018). Assim, o estudante compreenderá as questões históricas, sociais, políticas, climáticas, produção, recursos hídricos, solo e entre outras questões durante seu processo de formação formal, pois farão parte das diversas áreas do conhecimento científico (Brasil, 1998). Vale destacar, que no currículo escolar do ensino fundamental consta os temas formação de solo, relevo, clima, extrativismo, agropecuária, pesca, aquicultura, os sistemas de produção agrícola e inclusive da agricultura familiar (Bertholi, 2020). Esses, também são temas fundamentais para compreensão do contexto social e produtivo na Amazônia marajoara. Desse modo, discutir agroecologia em uma região de rios e florestas é de suma importância, tanto para os estudantes (Locatelli et al., 2020), quanto para os professores (Pinto et al., 2016). 
Assim, o caminho para o desenvolvimento da agroecologia deve passar, em primeiro lugar, pela educação (básica, superior, técnica e profissionalizante). Segundo Mitre et al. (2008), a união entre teoria e prática, representa a quebra de paradigmas educacionais, uma vez que propõe uma nova visão sobre o ensino, na qual traz a vivência como algo essencial no aprendizado. Por essa razão, a agroecologia se faz necessária em instituições de ensino (SOUSA et al., 2018; Petri \& Fonseca, 2020).

Vale ressaltar que experiências em agroecologia nas escolas vêm sendo relatadas em diversos estudos (Sousa, 2014; Leite \& Conceição, 2020; Nunes et al., 2020; Silva et al., 2020). Esses destacam a finalidade de fortalecer o ensino contextualizado. Diante do exposto, o objetivo desse trabalho foi avaliar a percepção de estudantes e professores sobre a agroecologia nas escolas da zona urbana e rural em Breves (Marajó-Brasil).

\section{Material e Métodos}

\section{1 Área de estudo}

A pesquisa foi realizada nas escolas do município de Breves, no arquipélago do Marajó, Pará, Brasil (Figura 1). O Marajó está localizado na costa amazônica (Amaral et al., 2012), nas coordenadas geográficas: $01^{\circ} 40^{\prime} 56^{\prime \prime}$ sul e $50^{\circ} 28^{\prime} 49^{\prime}$ " oeste (IBGE, 2019b). Constitui a maior ilha fluvio-marítima do mundo, com $49.606 \mathrm{~km}^{2}$ (IPEA, 2015). Uma região que compreende 16 municípios, os quais compõem as microrregiões de Arari (Cachoeira do Arari, Chaves, Muaná, Ponta de Pedras, Salvaterra, Santa Cruz do Arari e Soure), Furos de Breves (Afuá, Anajás, Breves, Curralinho e São Sebastião da Boa Vista) e Portel (Bagre, Gurupá, Melgaço e Portel).

Figura 1. Localização do município, bem como a identificação geográfica das escolas em Breves, Pará, Brasil.

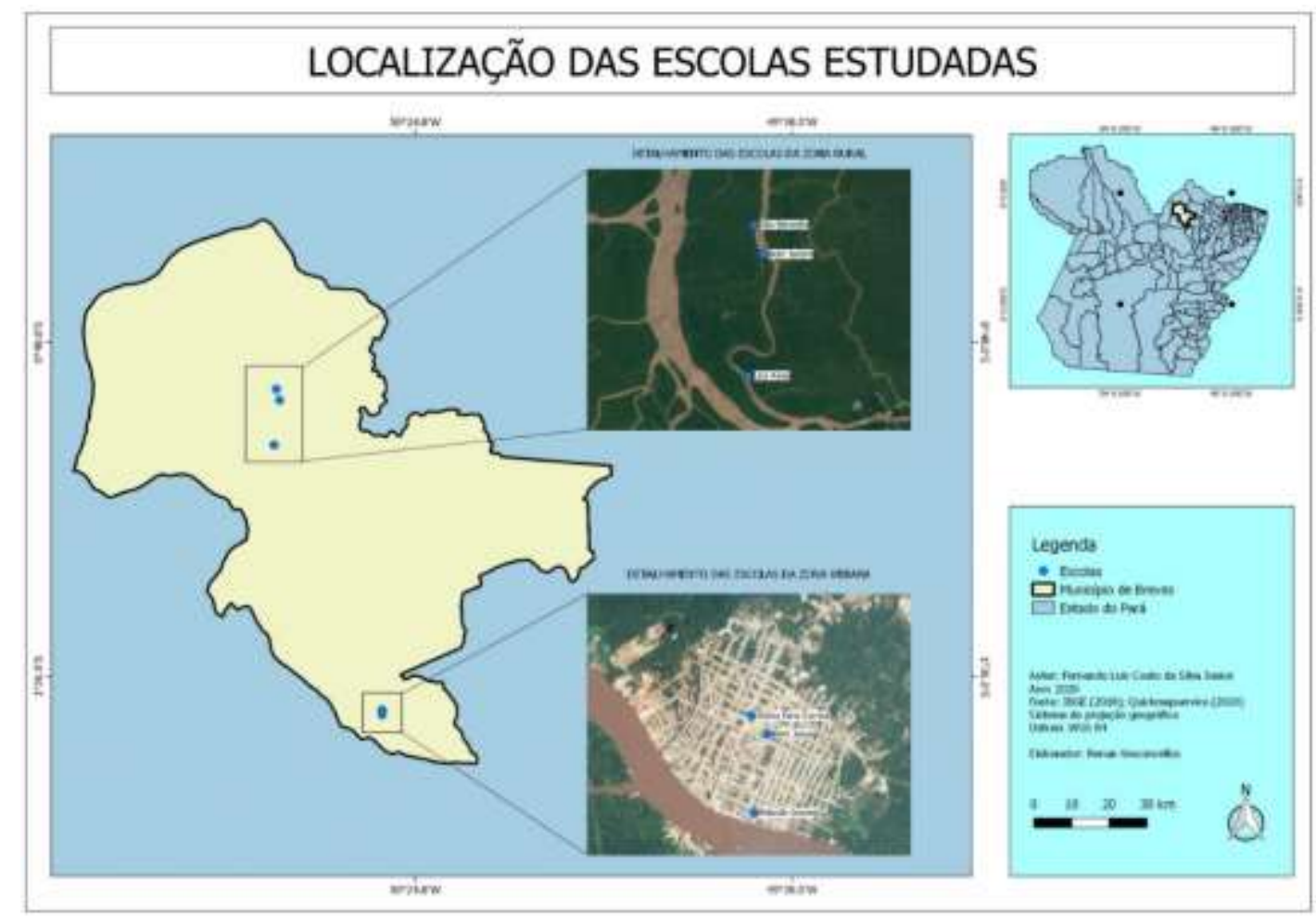

Fonte: Elaborado por Renan Vasconcelos.

Breves encontra-se ao sudoeste do arquipélago, com uma extensão territorial de 9.566,572 km² (IBGE, 2019a). Situase à margem esquerda do rio Parauaú. Cercado por diversas comunidades ribeirinhas em quase toda a sua extensão. A principal 
forma de acesso à Breves é por transporte fluvial, com duração média de 6 horas (lancha) ou 12 horas (navio/balsa) de viagem para a capital do Estado, Belém, e por via aérea em até 45 minutos de duração (Schaam \& Martins, 2010). O município é dividido em zona urbana e zona rural, com população bem distribuída, com cerca de 50\% vivendo em cada uma das áreas (IBGE, 2019b).

A zona rural do município é dividida em quatro distritos: Sede Rural, Antônio Lemos, São Miguel dos Macacos e Curumú. Breves é marcada pela diversidade de rios, florestas e fauna que ajudam na sobrevivência dos povos tradicionais da região. A economia do município é voltada para a exploração extensiva da extração de madeira, açaí (Euterpe oleracea Mart.), aquicultura e agricultura familiar (Schaam \& Martins, 2010). O presente trabalho foi conduzido em seis escolas do município de Breves, sendo três escolas na zona urbana e três na zona rural, com visitações locais entre janeiro e fevereiro de 2020 (Figura 2 ).

Figura 2. A: Escola Bom Jardim, Rio Jacarezinho; B: Escola Lica Alves, Rio Jacarezinho; C: Escola São Benedito, Rio Jacaré Grande; D: Escola Bom Jesus, Avenida Interventor Malcher; E: Escola Odízia Farias Gomes, Avenida Rio Branco; e F: Escola Estevão Gomes, Avenida Portel, em Breves, Pará, Brasil.

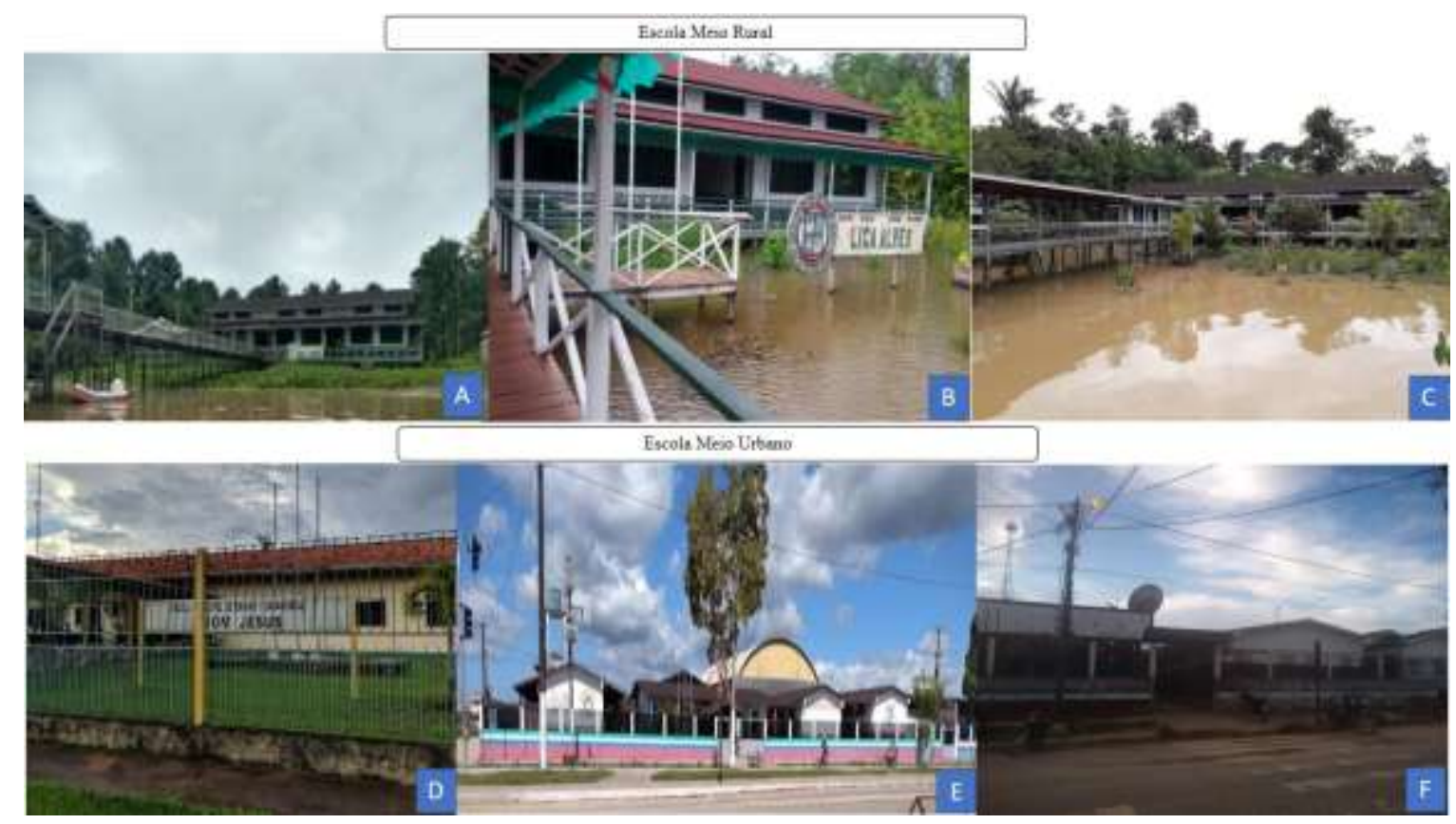

Fonte: Fernando Luís Couto da Silva Júnior, Edison Costa da Gama E Gerson Borges de Oliveira.

A pesquisa foi aplicada nas Escolas Municipais de Ensino Fundamental Odízia Farias Gomes, Bom Jesus e Estevão Gomes, todas elas localizadas na sede do município. As duas primeiras se localizam em bairros no centro e a terceira em um bairro da periferia da cidade. A outra parte da pesquisa foi realiza na zona rural, nas Escolas Municipais de Ensino Fundamental São Benedito, Bom Jardim e Lica Alves. O acesso às escolas que ficam nas áreas rurais ocorreu por meio de transportes fluviais. Vale destacar que a "rabeta" e a canoa são os meios de transporte mais utilizados pelos ribeirinhos que vivem no Marajó.

O percurso metodológico consistiu na pesquisa com estudantes e professores sobre o tema agroecologia, correspondendo a um estudo de caso. A metodologia da pesquisa foi descritiva e exploratória (Gil, 1996), que tem como procedimentos básicos para sua execução a pesquisa bibliográfica e documental, conforme Kripka et al. (2015). A investigação exploratória descritiva requer como atitudes fundamentais a abertura, a flexibilidade, a capacidade de observação e de interação com o grupo de investigadores e com os atores sociais envolvidos (Minayo, 2004). Essa investigação busca compreender e explicar a dinâmica das relações sociais que não podem ser quantificadas (Gerhardt \& Silveira, 2009).

Para a coleta dos dados quantitativos, aplicou-se questionários, conforme metodologia empregada por Gil (1999). Um instrumento que se destina a levantar informações escritas por parte dos sujeitos pesquisados, com vistas a conhecer a opinião 
dos mesmos sobre os assuntos em estudo (Severino, 2007). Assim, foram elaborados dois tipos de questionário: um destinado aos estudantes do $9^{\circ}$ ano do ensino fundamental (Apêndice I), sendo 24 aplicados na zona rural e 70 na zona urbana; e outro aos professores das disciplinas de geografia e ciências (Apêndice II), sendo 9 na zona rural e 7 na zona urbana, afim de identificar a percepção dos entrevistados, bem como, seus conhecimentos em agroecologia (Tabela 1).

Tabela 1. Questionários aplicados aos estudantes e professores sobre a agroecologia nas escolas em Breves, Pará, Brasil.

\begin{tabular}{ll}
\hline \multicolumn{1}{c}{ Perfil estudante } & \multicolumn{1}{c}{ Perfil professor } \\
\hline 1) Instituição, idade e gênero; & 1) Instituição, atuação, gênero e idade; \\
2) Conhecimentos sobre agroecologia; & 2) Conhecimentos sobre agroecologia; \\
3) Conhecimentos sobre agronegócio; & 3) Conhecimentos sobre agronegócio; \\
4) Conhecimentos sobre reforma agrária; & 4) Conhecimentos sobre agricultura familiar; \\
5) Conhecimentos sobre agricultura familiar; & 5) Didática sobre agroecologia e termos utilizados. \\
\hline
\end{tabular}

Fonte: Autores.

A identidade dos participantes foi mantida em sigilo, garantindo o anonimato e confidencialidade das informações. Os dados coletados foram analisados por meio de estatística descritiva (Prodanov, 2013), com auxílio do programa de gerenciamento de planilhas eletrônicas e apresentação por meio de gráficos.

\section{Resultados e Discussão}

\subsection{Percepção dos estudantes}

No presente estudo, a maioria dos estudantes entrevistados (60\% na zona urbana e $75 \%$ na zona rural) são do sexo masculino (Figura 3A) e apresentam idades que variaram entre as faixas de 14-15 e 16-17 anos, na zona urbana e rural, respectivamente (Figura 3B).

Figura 3. Gênero (A) e faixa etária (B) dos estudantes pesquisados em Breves, Pará, Brasil.

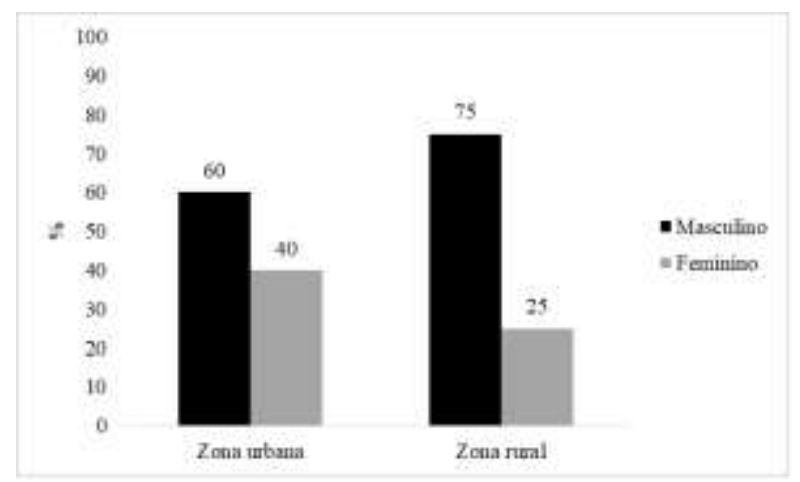

(A)

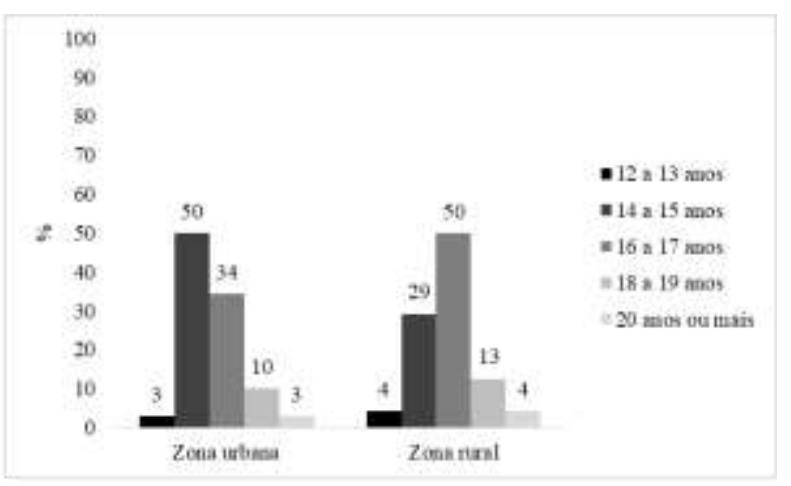

(B)

Fonte: Autores.

A desigualdade entre gêneros é predominante em diversas áreas, inclusive na educação, devido à inserção precoce das meninas no mundo do trabalho e, em muitos casos, a vivência prematura da maternidade que dificulta ou impede a conclusão do ensino fundamental. Tal predominância não está limitada ao acesso e nem ao desempenho dos alunos na escola, e sim ao discurso reforçado de supremacia masculina nesses ambientes (Colling, 2015). No entanto, a escola é uma instituição social que abrange a maior parte da população e, por isso, deve proporcionar um ambiente com ações transformadoras na relação entre mulheres e 
homens (Silva \& Silva, 2014).

Em relação à faixa etária dos estudantes que participaram dessa pesquisa, foi possível observar que a maioria dos alunos da zona urbana estão na idade considerada ideal/recomendada para cursar o $9^{\circ}$ ano (14 anos). Já os alunos da zona rural apresentam uma maior distorção idade-série, o que não ocorre apenas no município de Breves, pois segundo Instituto Nacional de Estudos e Pesquisas Educacionais Anísio Teixeira (INEP, 2020) essa é uma realidade da maioria dos municípios do Estado do Pará. O atraso desses alunos está atrelado a questões que envolvem o ambiente escolar, como infraestrutura, composição de turmas e práticas pedagógicas e, principalmente, às características da ausência do Estado brasileiro em implementar políticas públicas de educação que leve em consideração as especificidades de cada região, pois muitos alunos trabalham desde cedo, ou tem filhos e por conta disso precisam deixar a escola. Ademais, políticas públicas direcionadas às famílias desses alunos que garantissem recursos financeiros, empregabilidade, assistência técnica aos agricultores familiares, entre outras, contribuiriam para o rendimento escolar desses alunos e na redução da evasão escolar.

Os resultados do questionário retratando as informações referentes ao nível de conhecimento dos estudantes quanto a agroecologia; se já ouviram falar sobre essa temática; forma de abordagem da agroecologia em sala de aula; o significado da prática agroecológica, bem como as informações sobre os termos ecologia e agroecologia, nas escolas da zona urbana e rural no Marajó, são apresentados na Figura 4. 
Figura 4. Conhecimento em agroecologia (A), já ouviram falar em agroecologia (B), forma de abordagem da agroecologia em sala de aula (C), o significado da prática agroecológica (D), conhecimento sobre o termo ecologia (E) e conhecimento sobre o termo agroecologia (F) dos estudantes pesquisados, em Breves, Pará, Brasil.

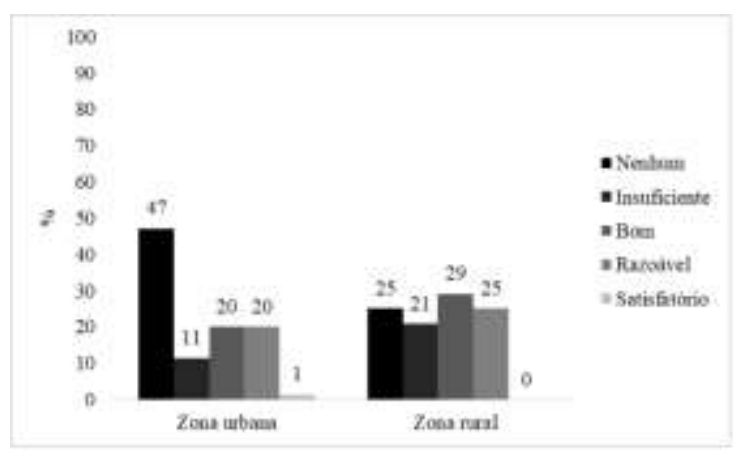

(A)

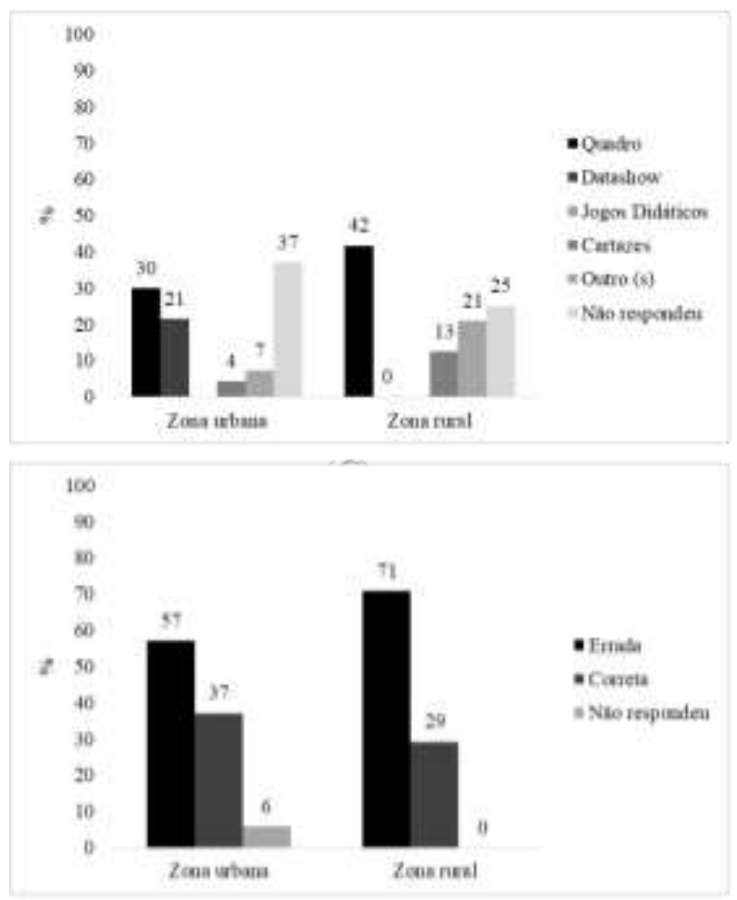

(E)

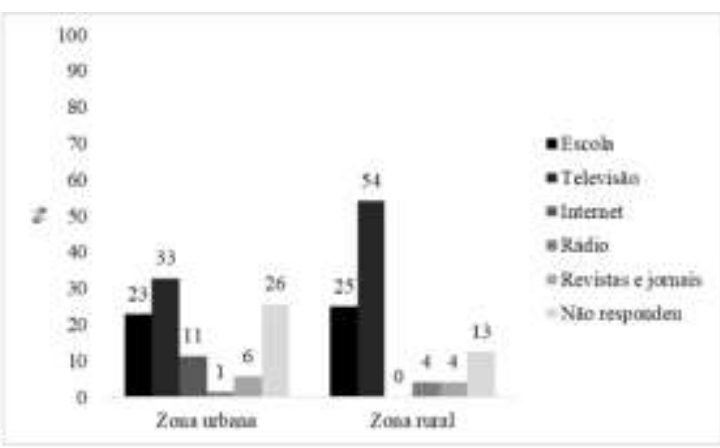

(B)

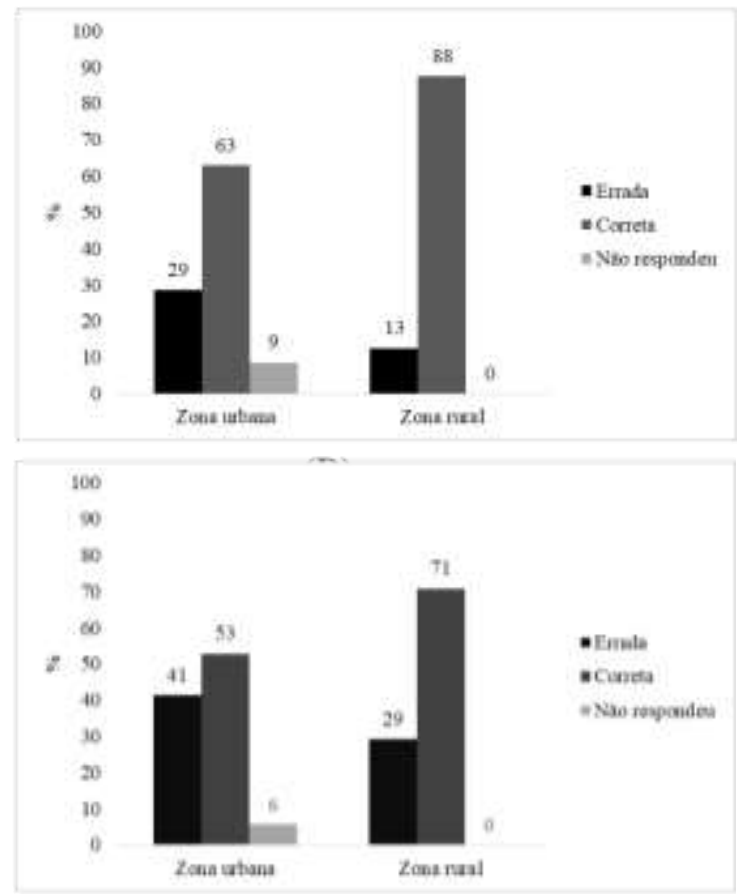

(F)

Fonte: Autores.

Nesse estudo, 47\% dos alunos da zona urbana não possuem conhecimento em agroecologia, número que chegou a apenas 25\% na zona rural (Figura 4A). Quando questionamos se já tinham ouvido falar sobre o assunto, a forma mais comum de acesso ao tema agroecologia foi via televisão com 33\% e 54\%, para estudantes da zona urbana e rural, respectivamente (Figura 4B). Resultados semelhantes foram encontrados por Sá-Oliveira et al. (2015), estudando a agroecologia nas escolas de Macapá, Amapá (Brasil). Isso demonstra que a referida ciência é multidisciplinar e possui abrangência quanto à utilização dos seus conhecimentos de forma contextualizada, podendo auxiliar no desenvolvimento sustentável de forma a permitir o êxito no processo de ensino-aprendizagem (Caporal \& Costabeber, 2002; Altieri, 2010; Koller \& Sobral, 2010; Sousa, 2014). Esses autores afirmam que a inserção do assunto nos meios de comunicação reflete a importância do tema agroecologia na atualidade.

A maioria dos estudantes da zona urbana e rural em Breves afirmou que a agroecologia foi abordada em sala de aula por meio do quadro (Figura 4C). Os recursos didáticos são considerados como facilitadores do processo de ensino-aprendizagem do conteúdo proposto, que deve ser aplicado pelo professor (Souza, 2007). No entanto, é notável a dificuldade das escolas 
públicas em diversificarem seus equipamentos de apoio e a necessidade de aumentarem a oferta de capacitação para os docentes. Esses fatos também impactam a frequência do estudante na escola (Pontili \& Kassouf, 2007).

Foi possível observar que os estudantes da zona rural possuem um maior conhecimento acerca do significado da prática agroecológica e sobre o termo agroecologia, quando comparados aos da área urbana (Figuras 4D e 4F). Essa diferença pode ser justificada pela maior afinidade com o campo. Possivelmente, a agroecologia é incentivada nas escolas rurais, enquanto os estudantes da zona urbana focam no estudo da vida em suas mais diversas formas, sobretudo valorizando a vida e a produção na cidade. Observamos que todos os estudantes pesquisados conhecem o tema. Isso mostra que o assunto está presente em seu cotidiano, porém falta um debate mais amplo sobre esse tema nas escolas, ou seja, de um maior incentivo para que haja o entendimento efetivo desses educandos, futuros profissionais. A agroecologia envolve o todo, as partes e suas interações, trazendo questionamentos, principalmente sobre a formação do profissional (Bica et al., 2007).

Em relação ao conhecimento sobre o termo ecologia, tanto os estudantes da zona urbana quanto da rural alegam não ter conhecimento sobre essa temática (Figura 4E). No entanto, destacamos que a ecologia deve ser estudada na disciplina de ciências e serve de base para agroecologia. Segundo Oliveira (2015), alunos de nível fundamental e médio devem ter tanto conhecimento teórico sobre sustentabilidade ecológica, quanto maturidade intelectual para discernir sobre o que é bom para o planeta e para a humanidade. Assim, saber como os alunos percebem o ambiente em que vivem, suas fontes de satisfação e insatisfação, bem como sobre os fundamentos da agroecologia, é de fundamental importância para a avaliação da conscientização da juventude a respeito das práticas ecologicamente corretas de produção de alimentos.

Observamos que no Marajó há vinculação dos estudantes com o meio rural, vivenciando uma realidade agropecuária e extrativista. Para Sá-Oliveira et al. (2015), a convivência dos alunos com a vida cotidiana do campo pode levá-los à preservação do meio ambiente e utilização de técnicas agrícolas menos agressivas.

As informações referentes ao nível de conhecimento dos estudantes em relação à revolução verde, à reforma agrária e à agricultura familiar são apresentadas na Figura 5 . 
Figura 5. Conhecimento em revolução verde (A), conhecimento sobre o conteúdo revoluçao verde (B), Conhecimento em reforma agrária (C), conhecimento sobre o conteúdo reforma agrária (D), Conhecimento em agricultura familiar (E) e conhecimento sobre o conteúdo agricultura familiar (F) dos estudantes pesquisados, em Breves, Pará, Brasil.

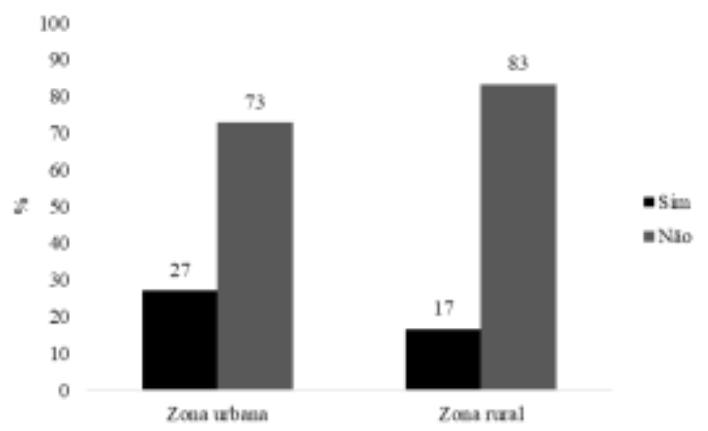

(A)

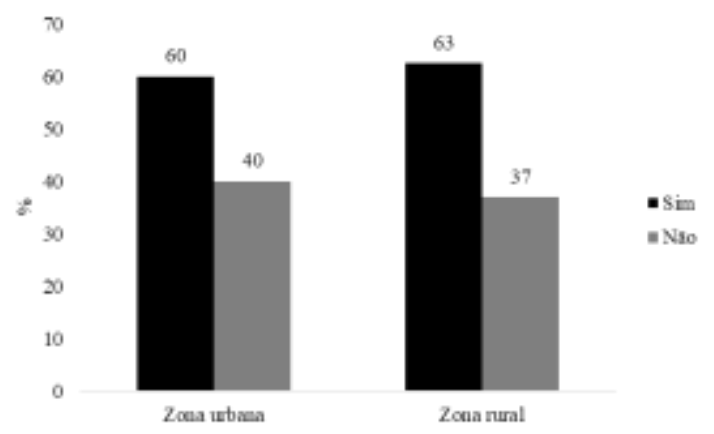

(C)

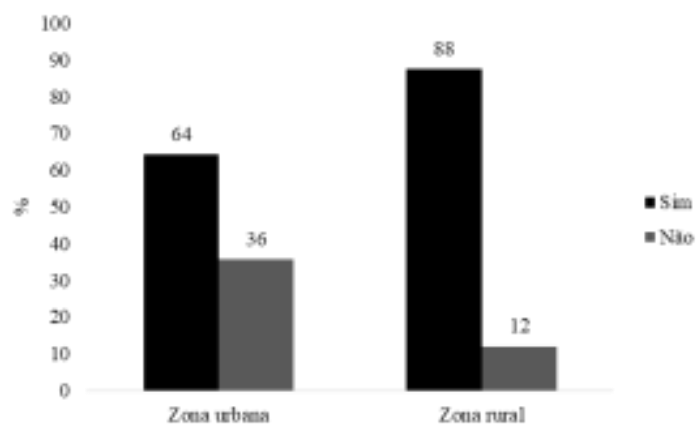

(E)

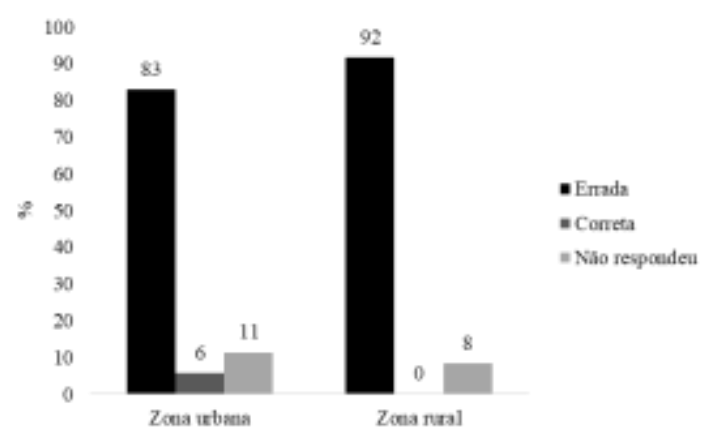

(B)

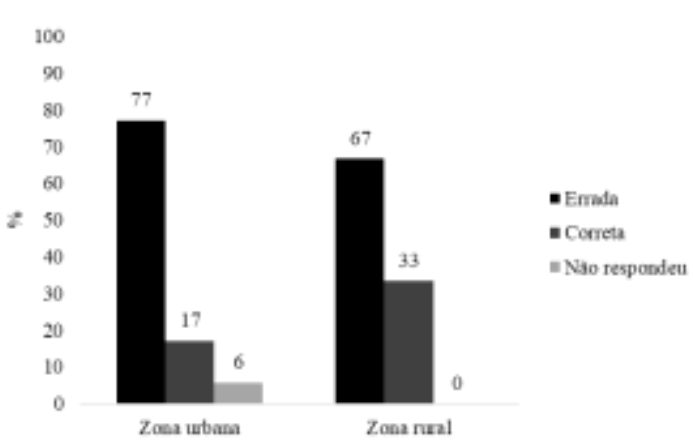

(D)

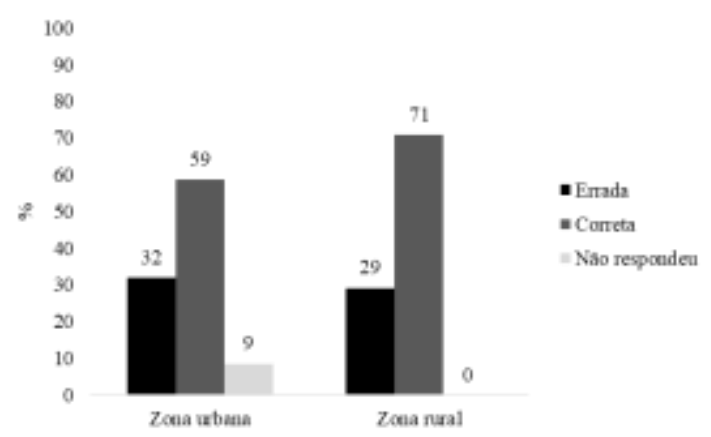

(F)

Fonte: Autores.

Os assuntos revolução verde (Figura 5A e 5B), reforma agrária (Figura 5C e 5D) e agricultura familiar (Figura 5E e 5F) são trabalhados nas escolas do Marajó de forma interdisciplinar. Para Caporal e Costabeber (2005), a agroecologia corresponde a um "campo de conhecimentos de natureza multidisciplinar". Portanto, a agroecologia nas escolas é um tema estratégico para a construção crítica acerca da política da agricultura convencional e distribuição agrária no Brasil, além de proporcionar conhecimento sobre agriculturas de bases ecológicas, podendo estabelecer um contraponto ao uso e apropriação não sustentáveis do solo (Silva \& Silva, 2014). A proposta interdisciplinar é importante no processo de ensino-aprendizagem, bem como para discutir a forma como essa articulação vem ocorrendo quando se trata de princípios de agroecologia (Locatelli Et al., 2020).

Observamos que a abordagem da agroecologia em conteúdo de diversas disciplinas, como história, geografia, biologia, entre outras, facilita a compreensão das relações humanas com o meio. Essa diversidade de perspectivas possibilita a diferenciação de modelos de apropriação do espaço, permitindo confrontar formas de pensar a produção de alimentos para o 
Marajó. Para Bica et al. (2007), não se pode pensar o ensino da agroecologia sem questionar o currículo escolar, que não deve ser monolítico e estático, mas ser composto por um agrupamento de conteúdo, no qual professores e estudantes determinam qual assunto dever ser complementado e aprofundado.

\subsection{Percepção dos professores}

No presente estudo, os professores eram predominantemente do sexo masculino e pertencentes ao ensino fundamental, na zona urbana e rural, em Breves (Figura 6A), com idade média de 35 anos, idade mínima de 22 anos e máxima de 58 anos (Figura 6B).

Figura 6. Gênero (A) e faixa etária (B) dos professores, em Breves, Pará, Brasil.

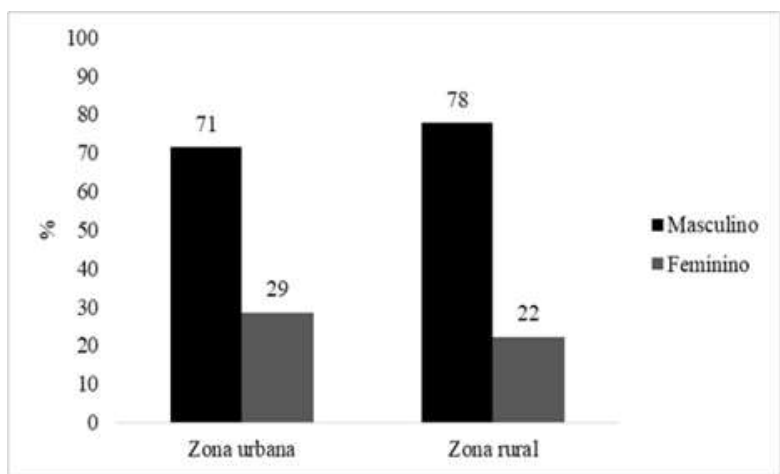

(A)

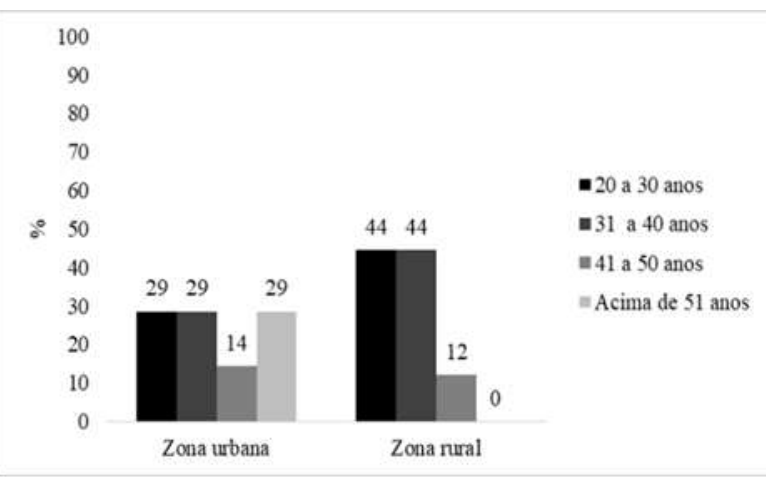

(B)

Fonte: Autores.

A cultura de discriminação de gênero ocidental colocou a mulher branca em um confinamento da vida privada e, dentro desse contexto, ela poderia exercer duas atividades: o magistério e a enfermagem. No entanto, somente as mulheres brancas de famílias com maior poder aquisitivo chegavam a exercer atividades trabalhistas; para as demais restava o trabalho doméstico e os cuidados com crianças e idosos (Colling, 2015). Isso não se aplica às mulheres negras, pois desde cedo exercem diferentes funções que vão desde trabalhos domésticos até o trabalho na agricultura (Nascimento, 2006). A luta por obtenção de cargos e igualdade de gênero e raça são avanços inegáveis. Apesar disso, entre os professores pesquisados percebemos que ainda existe uma grande disparidade entre os gêneros.

Em relação à faixa etária, foi possível observar que os professores do meio rural apresentaram idade inferior aos professores do meio urbano. Pressupõe-se que as dificuldades de locomoção, alojamentos, escolas adequadas e a distância entre familiares dificultam a presença de professores com idade avançada no meio rural. Além do fato de que muitos professores, quando atingem cinco anos no ensino rural, podem realizar o pedido de remoção para zona urbana. Uma característica que aumenta a presença de professores mais jovens no quadro da zona rural.

De acordo com Medeiros e colaboradores (2011), no Programa de Currículo Escolar Nacional, os conteúdos abordados por essa pesquisa devem ser trabalhados transversalmente nas disciplinas de Geografia e Ciências Físicas Biológicas (C.F.B). Em Breves, os professores participantes do presente estudo, $71 \%$ e $56 \%$ lecionam a disciplina de geografia nas escolas urbanas e rurais, respectivamente (Figura 7). Okonoski e Nabozny (2011) destacam as potencialidades para o debate das questões agroecológicas no ensino de geografia. 
Figura 7. Disciplinas ministradas pelos(as) professores(as), em Breves, Pará, Brasil.

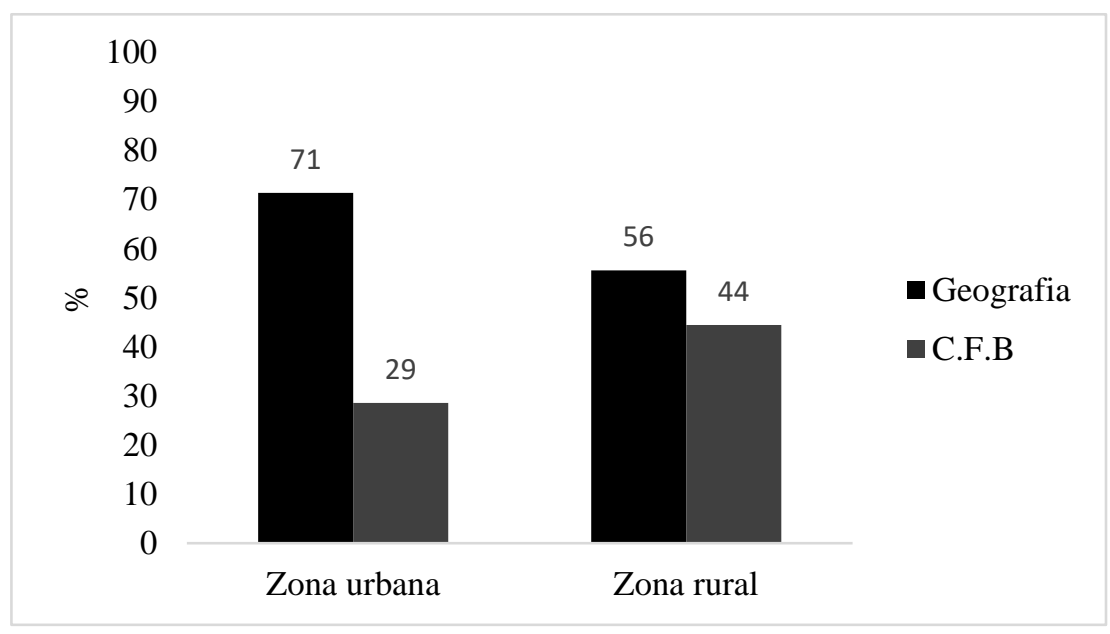

Fonte: Autores.

Essa disciplina possibilita compreender, na prática, como o cooperativismo e a agroecologia se estabelecem como estratégias fundamentais para a territorialização do campesinato (Finatto, 2020). Vale considerar que a geografia estuda as relações entre a sociedade e a natureza. Desse modo, tem sido problematizada a forma como essa relação tem acontecido na contemporaneidade e como poderá ocorrer no futuro, apontando-se, então, caminhos que a sociedade deve trilhar para um melhor relacionamento homem/natureza (Silva et al., 2016).

Ao analisar as informações dos professores quanto aos conhecimentos em agroecologia e se já ouviram falar em agroecologia (Figura 8), foi possível observar que eles possuem "bom" (zona urbana) e "razoável" (zona rural) conhecimento acerca do tema (Figura 8A). Essa diferença pode ser justificada pela maior afinidade do tema na zona rural, uma vez que a agroecologia estuda basicamente as interações dos seres vivos entre si e destes com o ambiente, enquanto na zona urbana focam no estudo da vida em suas mais diversas formas. Dentre os que não conhecem o tema, $14 \%$ são professores da zona urbana. O que revela que essa temática precisa ser melhor debatida na área urbana, ou seja, de mais momentos de reflexão e discussão tanto no processo de formação do professor quanto nos espaços escolares, além de formação continuada daqueles professores que já estão na ativa e não tiveram acesso aos debates relacionados a essa temática.

A pesquisa revelou que os professores já ouviram falar de agroecologia pela televisão e no ambiente acadêmico, tanto na zona urbana quanto na rural (Figura 8B). A agroecologia tem se destacado dentro das instituições (Sousa, 2017; Hage et al., 2018). No Brasil, ela aparece na forma de cursos de graduação, pós-graduação e cursos técnicos (Demarchi et al., 2011). A agroecologia vem se constituindo como uma das bases de um novo paradigma de desenvolvimento rural e, nessa abordagem, a extensão rural é um instrumento fundamental no processo de ensino-aprendizagem (Mello \& Oliveira, 2020). 
Figura 8. Professores que possuem conhecimento em agroecologia (A) e onde já ouviram falar em agroecologia (B), em Breves, Pará, Brasil.

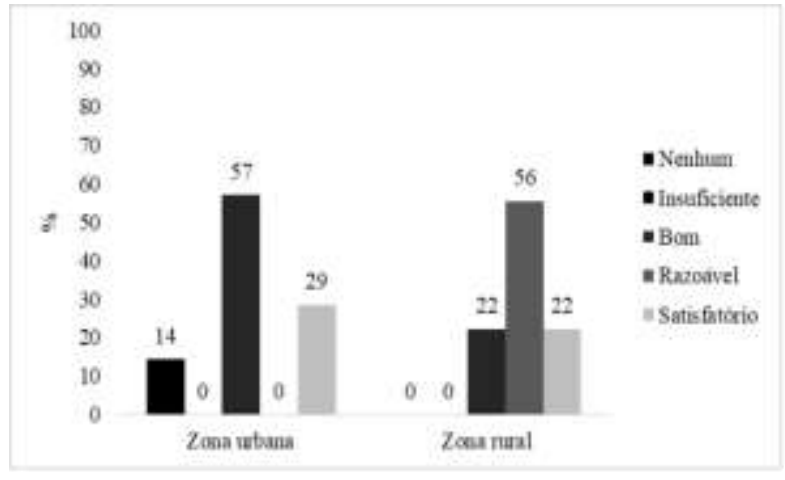

(A)

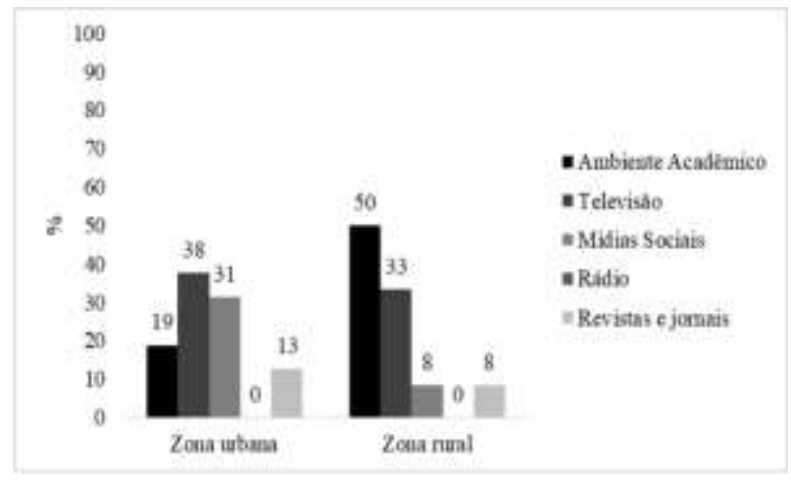

(B)

Fonte: Autores.

O percentual de professores que tem conhecimento sobre ecologia ainda permanece maior, demonstrando que esses docentes possuem certo domínio referente ao assunto. Com relação aos entrevistados que não conhecem o tema, $14 \%$ são da zona urbana (Figura 9A). Assuntos como a revolução verde e reforma agrária são reconhecidos pelos professores em Breves (Figura 9B e 9C). Todos os professores admitiram conhecer a agricultura familiar, mas, de acordo com a Figura 9D, mais de $56 \%$ dos professores da zona rural tiveram dificuldades em responder sobre onde está localizada a concentração de agricultura no Brasil. É interessante destacar esses dados, uma vez que a agricultura familiar é uma das bases da economia no Marajó. Portanto, é necessário que os docentes conheçam sobre ela para melhorar a dinâmica de suas aulas, associando a realidade local com o conteúdo ministrado.

Figura 9. Professores que possuem conhecimento em ecologia (A), revolução verde (B), reforma agrária (C) e agricultura familiar (D), em Breves, Pará, Brasil.

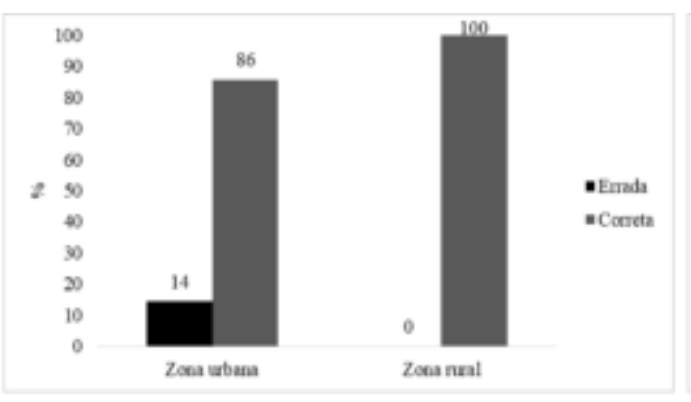

(A)

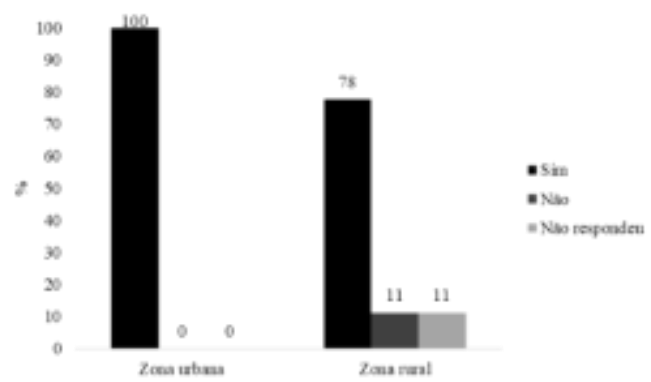

(C)

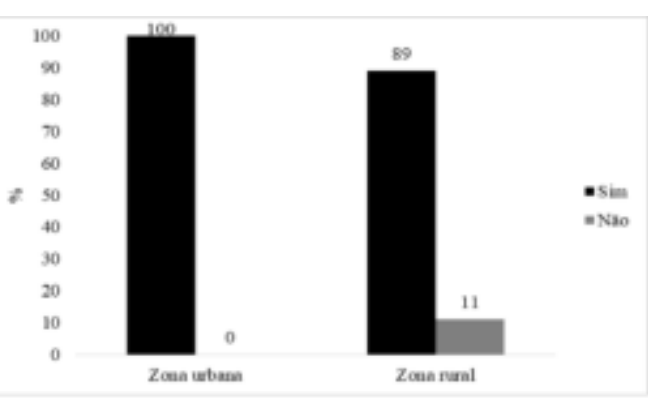

(B)

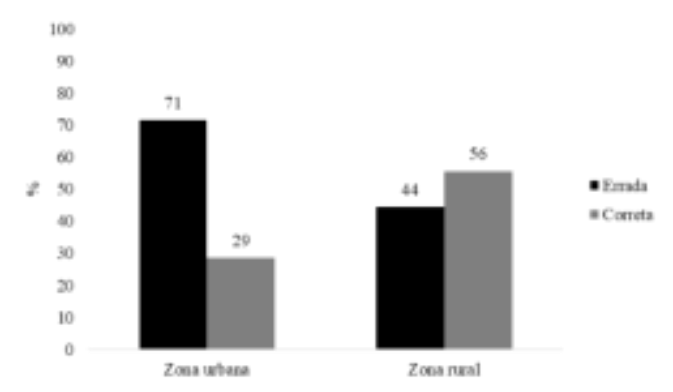

(D)

Fonte: Autores. 
Em relação à inserção dos conhecimentos da agroecologia em suas aulas, 43\% dos professores da zona urbana utilizam somente de maneira esporádica (Figura 10). Possivelmente, isso ocorre devido à falta de tempo durante as aulas, pois geralmente os currículos escolares priorizam conteúdos relacionados à vida urbana em detrimento daqueles que abordam a vida rural, além disso há carência de materiais didáticos para esse tipo de abordagem; falta de recursos didáticos; falta de formação continuada e pouco conhecimento sobre o assunto.

Figura 10. Utilização da agroecologia nas aulas por professores em Breves, Pará, Brasil.

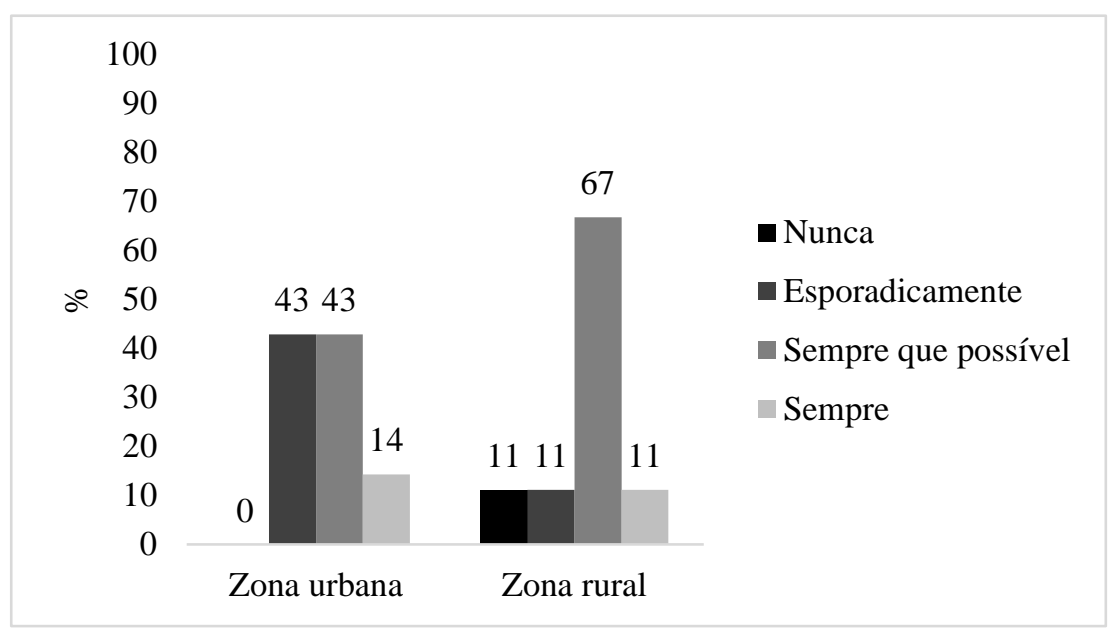

Fonte: Autores.

Em contrapartida, $67 \%$ dos professores da zona rural utilizam a agroecologia sempre que possível nas aulas. A vontade de enriquecer e diversificar as aulas; a necessidade de inovar a metodologia da aula; a dificuldade no ensino de algum conteúdo maçante ou complicado; as experiências anteriores; as sugestões de colegas de profissão; a proximidade do modo de vida dos alunos com a agroecologia, a aptidão ou gosto particular pela temática; e a concepção pedagógica da escola podem estar relacionadas à introdução da agroecologia na escola da zona rural.

No entanto, ainda existem professores que não trabalham ou raramente trabalham o tema com seus alunos e isso deve ser melhorado, uma vez que a agroecologia se mostra favorável para que ocorram mudanças de atitudes relacionadas à conservação dos recursos naturais. Segundo Leite e Conceição (2020), práticas educativas de introdução à agroecologia contribuem na sua incorporação e de dimensões socioambientais no trabalho educativo das escolas do campo vinculada à luta pela transformação das condições de vida local, ao mesmo tempo que acessam os conhecimentos acumulados pela humanidade.

Para Oliveira (2015), é necessário integrar o conhecimento do aluno nas práticas pedagógicas. Dessa forma, será possível garantir a melhoria da relação entre estudantes, professores e família e, também, a aprendizagem; principalmente quando tratamos da educação em escolas da área rural (educação do campo), pois, segundo a Lei de Diretrizes e Bases da Educação (LDB) 9394/96, devem ser realizadas adaptações para organizar o conteúdo e adequá-lo às necessidades e vivências dos alunos (Brasil, 1996).

Ressaltamos que a utilização da agroecologia em sala de aula é útil para o professor que deseja inovar a linguagem e a comunicação dos conhecimentos com os alunos, dinamizar e envolvê-los num processo de aprendizagem significativa. Além disso, de acordo com Locatelli et al. (2020), o uso da agroecologia nas aulas melhora a qualidade de ensino e aprendizado, oportunizando aos estudantes tornarem-se participantes desse processo e não meramente receptores de conhecimentos desconexos da realidade cotidiana. 


\section{Conclusão}

Ao final desse estudo, foi possível perceber a importância de investigar a percepção dos estudantes e professores do ensino fundamental (zona urbana e rural) sobre a agroecologia. Em Breves, os estudantes da zona rural possuem um maior conhecimento acerca do significado da prática e do termo agroecologia, quando comparados aos da zona urbana. Por outro lado, há falta de difusão da filosofia agroecológica nas escolas. Esse fato é reforçado quando analisamos a percepção dos professores.

Foi possível perceber que os docentes da zona rural utilizam com mais frequência os princípios da agroecologia como ferramenta para o ensino, em comparação aos da zona urbana. No entanto, essa prática deve ser mais incentivada para que o estudante compreenda melhor os assuntos e os relacione com sua futura vida profissional, visto que o Marajó tem como base da sua economia o agroextrativismo e a agricultura familiar.

Desse modo, é de suma importância atividades pedagógicas nas escolas marajoaras que trabalhem, problematizem e discutam o tema agroecologia, no sentido de fortalecer o ensino-aprendizagem dos educandos. Isso pode ser realizado de forma integrada ao currículo escolar, transversalmente ou através de uma abordagem transdisciplinar. Para tanto, são necessárias políticas públicas educacionais que valorizem o profissional da educação, proporcionem formação continuada e debates através de seminários, encontros de professores, oficinas ou minicursos que tenham como tema a agroecologia com o intuito de aproximar os seus conteúdos ministrados em sala de aula com a realidade do estudante.

\section{Agradecimentos}

Ao Instituto Federal de Educação, Ciência e Tecnologia do Pará (IFPA), Campus Breves, pela oportunidade de concluir o curso de Especialização em Agroextrativismo Sustentável e Desenvolvimento Rural. Aos estudantes e professores em Breves, pela colaboração na pesquisa realizada para monografia, que originou os resultados aqui apresentados.

\section{Referências}

Altieri, M. A. (2010). Agroecologia, agricultura camponesa e soberania alimentar. Revista NERA, 13 (16), 22-32.

Amaral, D. D., Mantelli, L. R., \& Rossetti, D. F. (2012). Palaeoenvironmental control on modern forest composition of southwestern Marajo Island, Eastern Amazonia. Water and Environment Journal, 26, 70-84.

Barbosa, M. M. C., \& Araujo, R. C. (2016). Educação Profissional e Tecnológica na Amazônia marajoara: a experiência do IFPA Campus Breves. Anais... In: II Seminário Nacional de Educação em Agroecologia, 2016, Rio de Janeiro. Educação em Agroecologia.

Bertholi, A. W. (2020). Geografia Agrária em Debate: das lutas históricas às práticas agroecológicas (2017). Revista Verde Grande - Geografia e Interdisciplinaridade, 2 (1), 132-136.

Bica, G. S., Hoeller, S., Gandin, R. V., \& Paglia, E. C. (2007). Educação e agroecologia: caminhos que se completam. Revista Brasileira de Agroecologia, 2 (2), 1576-1579.

Brandão, C. R. (1993). O que é educação. (28a ed.), Brasiliense, Coleção Primeiros Passos.

Brasil (1996). Lei de Diretrizes e Bases da Educação Nacional. Lei No 9.394 de 20 de dezembro de 1996. Brasília, DF: Presidência da República. http://www.planalto.gov.br/ccivil_03/LEIS/L9394.htm.

Brasil (1998). Secretaria de Educação Fundamental. Parâmetros curriculares nacionais: geografia. Brasília: MEC/ SEF, 156 p.

Burigo, A. C., \& Porto, M. F. S. (2019). Trajetórias e aproximações entre a saúde coletiva e a agroecologia. Saúde Debate, 43 (8), $248-262$.

Caporal, F. R., \& Costabeber, J. A. (2002). Agroecologia: enfoque científico e estratégico. Agroecologia e Desenvolvimento Rural Sustentável, 3 (2), 13-16.

Caporal, F. R. (2009). Agroecologia: uma ciência do campo da complexidade. Brasília: Gervásio Paulus, 111p.

Caporal, F. R., \& Costabeber, J. A. (2005). Agroecologia. Enfoque científico e estratégico. Agroecologia e Desenvolvimento Rural Sustentável, 3 (2), $13-16$.

Castro, F., Funtemma, C. (2015). Governança Ambiental no Brasil: Entre o Socioambientalismo e a Economia Verde. Jundiaí, SP: Paco Editorial.

Colling, A. M. (2015). Inquietações sobre educação e gênero. Revista Trilhas da História, 4 (8), 33-48. 
Demarchi, L. O., Leme, M. K., Bredariol, L. R., \& Dombrowsky, M. Y. (2011). Discutindo a agroecologia na universidade: grupo de extensão em agroecologia "Gira-Sol, Cadernos de Agroecologia, 6 (2), 1-5.

Freitas, J. P., Patrício, M. C. M., Vasconcelos, R. F. V., Silva, V. M. A., Santos, E. D., \& Freitas, F. E. (2013). Produção agroecológica integrada e sustentável - pais: experiência vivenciada por alunos da escola municipal Gustavo Adolfo Cândido Alves Campina Grande/PB. Polêmica, 12 (2), 369-379.

Finatto, R. A. (2020). Trabalho de campo em geografia agrária: produzindo conhecimento sobre campesinato, cooperativismo e agroecologia. Revista Brasileira de Educação em Geografia, 10 (19), 548-569.

Gerhardt, T. E., \& Silveira, D. T. (2009). Métodos de pesquisa. Editora da UFRGS.

Gil, A. C. (1999). Métodos e técnicas de pesquisa social. (5a ed.), Atlas.

Gil, A. C. (1996). Como elaborar projetos de pesquisa. (3a ed.), Atlas.

Hage, S. M., Molina, M. C., Silva, H. S. A., \& Anjos, M. P. (2018). O direito à educação superior e a licenciatura em educação do campo no Pará: riscos e potencialidades de sua institucionalização. Acta Scientiarum. Education (Online), 40, 1-13.

IBGE (2019a). Instituto Brasileiro de Geografia e Estatística. Censo Agropecuário 2017: resultados definitivos. Rio de Janeiro: IBGE.

IBGE (2019b). Instituto Brasileiro de Geografia e Estatística. Panorama Cidade Breves/Pará. População, Território e ambiente.

IPEA (2015). Instituto De Pesquisa Econômica Aplicada. Observatório da Função Socioambiental do Patrimônio da União na Amazônia: Relatório Territorial do Marajó. Rio de Janeiro: IPEA.

INEP - Instituto Nacional de Estudos e Pesquisas Educacionais Anísio Teixeira (2020). Resumo Técnico: Censo da Educação Básica Estadual 2019. Brasília: Instituto Nacional de Estudos e Pesquisas Educacionais Anísio Teixeira.

Koller, C., \& Sobral, F. (2010). A construção da identidade nas escolas agrotécnicas federais: a trajetória da COAGRI ao CONEAF. In: Moll, J. (Org.). Educação profissional e tecnológica no Brasil contemporâneo: desafios, tensões e possibilidades. Artmed.

Kripka, R., Scheller, M., \& Bonotto, D. L. (2015). Pesquisa documental: considerações sobre conceitos e características na pesquisa qualitativa. In: Anais... Congresso Ibero-Americano em Investigação Qualitativa, 4, Atas, 2, 243 - 247.

Leite, V. J., \& Conceição, L. A. (2020). Práticas educativas de introdução a agroecologia nas escolas itinerantes do campo do Paraná. Ambiente \& Educação, 25 (2), 19-49.

Locatelli, A., Santos, K. F., \& Rosa, C. T. W. (2020). Atividades experimentais com enfoque em agroecologia na perspectiva da educação no campo. Areté, 13 (27), 1-16.

Luz, L. A., \& Quiñones, E. M. (2012). Agroecologia: uma ciência na busca pelo desenvolvimento agrícola sustentável. Revista Ceciliana, 4 (1), $52-54$.

Medeiros, A. B., Mendonça, M. J. S. L., Souza, G. L., \& Oliveira, I. P. (2011). A importância da educação ambiental na escola nas séries iniciais. Revista Faculdade de Montes Belos, 4 (1), 1-17.

Mello, A. P. O. A., \& Oliveira, R. E. (2020). Extensão Rural Agroecológica: experiências para (trans) formação no ensino superior em agroecologia. Revista ELO-Diálogos em extensão, 9, 1-7.

Minayo, M. C. S. (2004). O Desafio do Conhecimento. Hucitec.

Mitre, S. M., Siqueira-Batista, R., Girardi-De-Mendonça, J. M., Morais-Pinto, N. M., Meirelles, C. A. B., Pinto-Porto, C., Moreira, T., \& Hoffmann, L. M. A (2008). Metodologias ativas de ensino-aprendizagem na formação profissional em saúde: debates atuais. Ciências saúde coletiva [online], 13, $2133-2144$.

Nascimento, B. (2006). A mulher negra no mercado de trabalho. In: RATTS, A. Eu sou atlântica: sobre a trajetória de vida de Beatriz Nascimento. São Paulo: Instituto KUANZA, Imprensa Oficial.

Nunes, L. R., Rotatori, C., \& Cosenza, A. (2020). A horta escolar como caminho para a agroecologia escolar. Revista Sergipana de Educação Ambiental, 9 (1), $1-21$.

Okonoski, T. R. H., \& Nabozny, A. (2011). Agroecologia no ensino da geografia: Relato... Estágio Supervisionado, práticas. Para Onde!?, 5 (1), 16-35.

Oliveira, C. D. S. (2015). O aluno do campo na escola urbana e sua diversidade cultural. 56 p. Trabalho de Conclusão de Curso (Especialização) - Universidade Federal do Pampa, Especialização em Educação e Diversidade Cultural.

Petri, M., \& Fonseca, A. B. (2020). Entre a educação ambiental e a agroecologia: um olhar sobre escolas famílias agrícolas (EFAS). Ambiente \& Educação, 25 (2), 369-392.

Pinto, D. S., Amador, F., Oliveira, L. M. T., \& Campos, M. (2016). A formação de professores para a Agroecologia e a experiência do curso de Licenciatura em Educação do Campo da UFRRJ. Cadernos de Agroecologia, 11 (1), 1-9.

Pontili, R. M., \& Kassouf, A. L. (2007). Fatores que afetam a frequência e o atraso escolar, nos meios urbano e rural, de São Paulo e Pernambuco. RER, 45 (01), 027-047.

Prodanov, C. C. (2013). Metodologia do trabalho científico: métodos e técnicas da pesquisa e do trabalho acadêmico. (2a ed.), Feevale.

Schaam, D. P., \& Martins, C. P. (2010). Muito além dos campos: arqueologia e história na Amazônia Marajoara. Gknoronha. 
Research, Society and Development, v. 10, n. 1, e58210111961, 2021 (CC BY 4.0) | ISSN 2525-3409 | DOI: http://dx.doi.org/10.33448/rsd-v10i1.11961

Santos, L. A. C. (2020). Agroecologia e conhecimento tradicional: uma análise bibliométrica. Tecnia, 5 (1), $153-179$.

Sá-Oliveira, J. C., Vasconcelos, H. C. G., \& Silva, E. S. (2015). A Agroecologia na percepção de alunos de ensino médio de quatro escolas públicas na cidade de Macapá-Amapá. Biota Amazônia, 5 (3), 98-107.

Severino, A. J. (2007). Metodologia do Trabalho Científico. (23a ed.), Cortez.

Silva, F. S., Veras, G. S., Soares, M. A., Rocha, P. Q., Santos, J. R. S., \& Almeida, R. S (2016). Horta Escolar Agroecológica: Alternativas ao ensino de geografia e consciência ambiental no povoado Jardim Cordeiro, Delmiro Gouveia / AL. Diversitas Journal. 1 (1), 337-346.

Silva, L. F., Barros, R. P., Pinheiro, R. A., Silva, J. E., Cabral, M. J. S., \& Lima, J. S. (2020). Agroecologia e horta escolar como ferramentas de educação ambiental e produção de alimentos naturais. Diversitas Journal, 5 (1), $27-33$.

Silva, M. H. C. R., \& Silva, L. C. S. (2014). O tema agroecologia nos livros didáticos de geografia do ensino fundamental II. Revista de Ensino de Geografia, 5 (8), 85-95.

Souza, E. E. (2007). O uso de recursos didáticos no ensino escolar. Anais... In: I Encontro de Pesquisa em Educação, IV Jornada de Prática de Ensino, XIII Semana de Pedagogia da UEM: "Infância e Práticas Educativas". Maringá.

Sousa, R., Costa, R., Chagas, H., \& Cruz, R. (2018). O trabalho como princípio educativo. RTPS - Revista Trabalho, Política e Sociedade, 3 (4), $189-206$.

Sousa, R. P. (2017). Agroecologia e educação do campo: desafios da institucionalização no Brasil. Educação \& Sociedade (Impresso), 38, 631-648.

Sousa, R. P. (2014). Formación Profesional de Camponeses en una Escuela en la Amazonia Brasileña. Agroecología, 9 (1y2), $31-44$. 